\title{
Uptake of p-Nitrophenol (PNP) from model aqueous solutions using raw and quaternised Afromomum melegueta peels
}

\author{
Ndiritu J. ${ }^{{ }^{*}}$, Mwangi I. W. ${ }^{2}$, Murungi J. I. ${ }^{2}$, Wanjau R. N. ${ }^{2}$ \\ ${ }^{1 *}$ Department of Biological \& Physical Sciences, Turkana University College, P.O Box 69-30500, Lodwar, Kenya \\ ${ }^{2}$ Chemistry Department, Kenyatta University, P.O Box 43844-0100, Nairobi, Kenya \\ ${ }^{1 *}$ Corresponding Author. Email: jndiritun82@gmail.com
}

Received: 8 July 2020 / Accepted: 28 September 2020 / Published online: 20 November 2020

\begin{abstract}
Anthropogenic activities contribute large amounts of pollutants to the environment which threaten animal and human health. There is increased realization of the effect of these toxins on surface and ground water, consequently, their elimination is vital in rendering secure water for drinking as well as culpable release of effluents to our habitats. Phenolic compounds cause serious health effects to both humans and animals; a $p$-Nitrophenol concentration of $1 \mathrm{ppb}$ changes the taste and odour of water as well as meat and fish quality. In humans, exposure to PNP causes eye and skin burns while its interaction with blood leads to confusion, cyanosis and unconsciousness. It is imperative therefore to find ways for removing PNP from water. Among the available techniques for removing PNP from water, adsorption is more convenient and offers more advantages because of its design, simplicity, and operating flexibility. The present study involved application of peels of raw Afromomum melegueta (RAM) and quaternised Afromomum melegueta (QAM) to remove PNP from water through adsorption. The raw adsorbents were modified with a quaternary ammonium salt to improve their uptake efficiency. The impact of experimental parameters; contact time, $\mathrm{pH}$, sorbent dose, temperature and concentration were investigated. Attenuated FTIR technique was employed to characterize the adsorbent materials. It was established that the quaternary ammonium compound was anchored chemically within the cellulose structure of Afromomum melegueta peels. The behavior of adsorption of PNP was investigated using Langmuir and Freundlich isotherm models. The physical sorption load was 8.70 and $106.38 \mathrm{mg} / \mathrm{g}$ for RAM and QAM peels respectively from Langmuir adsorption equation. Uptake of PNP is high at
\end{abstract}

the first 30 mins of contact and at sorbent dosage of 0.01 $\mathrm{g}$ and $0.03 \mathrm{~g}$ for RAM and QAM respectively. Quantity of PNP removed increases as the initial concentration rises however, adsorption decreases after a concentration exceeding $30 \mathrm{mg} / \mathrm{L}$. The ideal $\mathrm{pH}$ and temperature for PNP removal is at $\mathrm{pH} 3$ and $25^{\circ} \mathrm{C}$ respectively. In conclusion, the findings suggest that Afromomum melegueta peels can be friendly to the environment, cheap biosorbents and efficient which can be applied for the uptake of PNP from drinking water

Key Words: Afromomum melegueta, Adsorption, quaternised, $p$-Nitrophenol, Isotherms

\section{INTRODUCTION}

Phenolic compounds contain one or more hydroxyl group directly bonded to a benzene ring (Mwangi et al., 2014). These compounds dissociate easily in aqueous solution and are more acidic than corresponding alcohols since the $\mathrm{O}-\mathrm{H}$ bond is weak in phenols as a result of a pool of mobile electrons that causes the ring to be stable by withdrawal of electron by the different ring substituents (Crisponi et al., 2002). Further, phenolic compounds exhibit different properties due to the presence of different bonded substituents as well as other functional groups (Crisponi et al., 2002). Dissolution of most phenolic compounds yields the corresponding phenolate ion, with the insoluble phenolic compounds disintegrating to give simpler water soluble phenolic compounds which can eventually find their way into various water bodies and cause pollution (Mwangi et al., 2014). 
Dissolution of PNP in water yields an aqueous solution that is slightly acidic. Consequently, PNP is a central chemical compound in a host of industrial processes which include: pesticide, petrochemical, pharmaceutical, dyes and paints, oil refineries, plastics, pulp and paper mill, hence effluents generated from such industries will contain PNP (Ahmad et al., 2011). The effluents containing PNP will then be deposited in soil and water thus causing pollution (Parida \& Prakasini, 2004). ATSDR (1992) reported that PNP is an eye irritant while on ingestion or inhalation brings about vomiting, sleepiness, headaches, and ataxia. Recently PNP was reported by US Environmental Protection Agency to be one of the most poisonous, bioaccumulative and indestructible organic compound which causes adverse effects to humans and animals even at negligible concentrations (Abdel-Ghani et al., 2016).

In view of the environmental impacts of PNP on humans and animals, appreciable research work has been done aimed at effective removal of PNP or the reduction of its concentration from aqueous media. It is therefore imperative to develop cheaper methods for removing PNP from water to the developing communities through preparation of alternative adsorbents from locally available materials and which are renewable. Among the materials that has not been exploited for water remediation is Afromomum melegueta. This plant is herbaceous and grows in swampy habitats, its fruits are purple and are trumpetshaped with many small, reddish-brown aromatic seeds (Ilic et al., 2010). In Kenya, the fruit is abundant in Chogoria, Tharaka-Nithi County and other parts of Meru County. In the present study, the peels of this fruit were utilized in their raw and modified forms for the uptake of PNP from water.

\section{MATERIAL AND METHODS}

\section{Chemicals, reagents and solvents}

The reagents used were of analytical grade and all the solutions were prepared in distilled-deionized water at chemistry laboratory of Kenyatta University in Nairobi, Kenya. The phenolic compound used was $p$-Nitrophenol (PNP). Other reagents included: propylene oxide, epichlorohydrin, polyDADMAC, sodium hydroxide, hydrochloric acid, ammonium acetate and methanol. Stock solutions of $1000 \mu \mathrm{g} / \mathrm{L}$ concentration of PNP were prepared in ammonium acetate buffer solution from which working solutions were obtained. The $\mathrm{pH}$ of working solutions was adjusted with either $0.1 \mathrm{M}$ sodium hydroxide or $0.1 \mathrm{M}$ hydrochloric acid.

\section{Preparation of the quartenised adsorbents}

The Afromomum melegueta peels were collected locally and were transported to the laboratories, washed thoroughly with deionized water to purify them, then chopped into pieces before they were oven dried at $105^{\circ} \mathrm{C}$ to eliminate moisture. The adsorbents were ground into powder and sieved. The resulting solids were labeled and kept in desiccators until used. The ground adsorbents were then chemically modified using method described by Mwangi et al. (2014). The dry powder of Afromomum melegueta peels was activated for $12 \mathrm{hrs} ; 280 \mathrm{~g}$ of this sample was transferred into a two litre three necked flask after which $420 \mathrm{~cm}^{3}$ of $0.625 \mathrm{M} \mathrm{NaOH}$ was added. A solution made by dissolving $16.8 \mathrm{~cm}^{3}$ of epichlorohydrin in $140 \mathrm{~cm}^{3}$ of propylene oxide was introduced into the flask contents. Thorough stirring of the mixture was done until all the liquid had dried and there was no more enlargement of the material. This reaction was carried out at a temperature of $25^{\circ} \mathrm{C}$ and gradually raising it to $50^{\circ} \mathrm{C}$ for 1 hour in a thermostatic water bath. Epoxidation procedure followed is coherent with the one used by Bortolini et al. (2002). A mixture of $40 \mathrm{~g}$ solid sample of hydroxypropylated Afromomum melegueta peels and the epoxidated polyDADMAC at $4{ }^{\circ} \mathrm{C}$ were placed in a $500 \mathrm{~cm}^{3}$ three neck flask after which $2.8 \mathrm{~g}$ of sodium hydroxide was added and the mixture agitated intensively for 30 mins. The agitation continued for further 6 hours at $60{ }^{\circ} \mathrm{C}$ while maintaining the $\mathrm{pH}$ above 8 (Bortolini et al., 2002). Finally, the mixture was filtered by vacuum filtration to obtain the residue which was washed using distilled water to lower the $\mathrm{pH}$ to 7 . The modified adsorbent material was air dried. The two adsorbents; the raw Afromomum melegueta (RAM) and quaternised Afromomum melegueta (QAM) were later characterized using FTIR.

\section{Instrumentation}

The raw and quaternised adsorbents were characterized using a Shimadzu Fourier transform infrared (FTIR-IR tracer-200) spectrophotometer to identify the functional groups contained in the raw and modified adsorbents (Han et al., 2010). The PNP concentration in water was obtained using a double beam UV-Vis spectrophotometer (Model Specord 200, Analytik Jena) at maximum solution wavelength of $318 \mathrm{~nm}$.

\section{Optimization of adsorption parameters}

Influence of parameters: contact time, $\mathrm{pH}$, initial PNP concentration, amount of sorbent and temperature on uptake efficiency of the raw and quaternised sorbents was done by maintaining other parameters stable while changing the one under investigation (Mwangi \& Ngila, 2012). Variation of process parameters was done as follows; solution $\mathrm{pH}(3-9)$, contact time (1 - $150 \mathrm{~min})$, sorbent dose $(0.01-0.06 \mathrm{~g})$, initial PNP concentration $(5-100 \mathrm{mg} / \mathrm{L})$ and temperature $\left(15-90^{\circ} \mathrm{C}\right)$ in $20 \mathrm{~mL}$ aqueous solution. 


\section{RESULTS AND DISCUSSION}

\section{FTIR characterisation}

The results from FTIR spectrum of RAM and QAM indicated the presence of a narrow band at 3425. 58 $\mathrm{cm}^{-1}$, this is characteristic of the existence of stretching vibrations of $-\mathrm{OH}$ or $-\mathrm{NH}$ groups (Stuart, 1996) while the signal at $2924.09 \mathrm{~cm}^{-1}$ in RAM and QAM are attributed to - $\mathrm{CH}$ stretches and hydroxyl group in a carboxylic acid. The signal at $1458 \mathrm{~cm}^{-1}$ was assigned to $-\mathrm{OH}$ stretches in carboxylic acids while the peak at $1110 \mathrm{~cm}^{-1}$ was assigned to an organic siloxane or silicone. Absorbance at $2276 \mathrm{~cm}^{-1}$ in QAM was assigned to isocyanate stretch while the peak at $1373.32 \mathrm{~cm}^{-1}$ in QAM was assigned to aliphatic nitro compounds. The signal at $1265.30 \mathrm{~cm}^{-1}$ in QAM could be due to aromatic ethers or aryl-O stretch functional group. The peak at $1458 \mathrm{~cm}^{-1}$ in RAM was allocated to $-\mathrm{OH}$ stretch in carboxylic acids while the peak at $1064.71 \mathrm{~cm}^{-1}$ was assigned to primary amine $-\mathrm{NH}$ stretch. The band at $1519.91 \mathrm{~cm}^{-1}$ can be attributed to an aromatic ring of lignin in the RAM; this band disappears in the QAM suggesting a reaction of depolymerization of aromatic ring of lignin that could have led to removal of lignin (Merkel et al., 2014). In QAM the appearance of the peak at 2345.44 $\mathrm{cm}^{-1}$ after modification is attributed to an amine group, $-\mathrm{NH}_{4}{ }^{+}$or its derivatives. The band at $1651.36 \mathrm{~cm}^{-1}$ moved to $1627.92 \mathrm{~cm}^{-1}$ owing to $\mathrm{NH}_{2}$ deformation of amines, the signal at $1458.18 \mathrm{~cm}^{-1}$ in RAM relocated to 1435.04 $\mathrm{cm}^{-1}$ (Pavia et al., 1996). The FTIR spectra for the raw and quaternised adsorbents is presented in Figure 1.

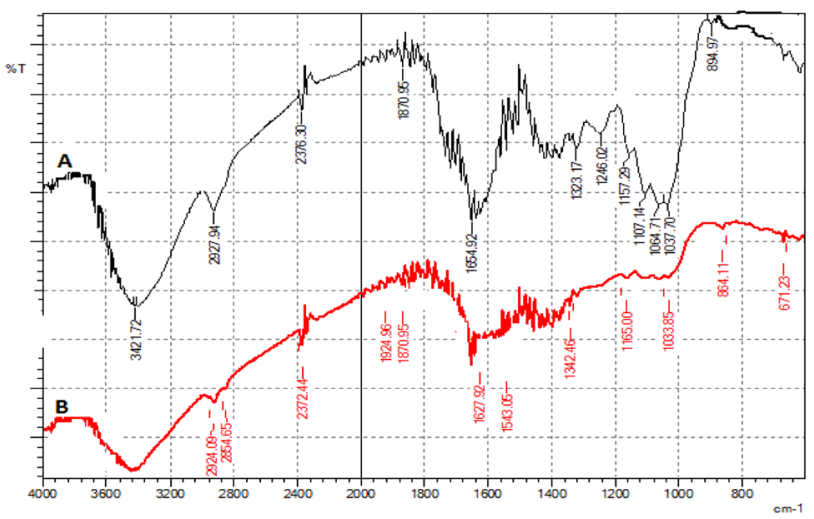

Figure 1. FTIR spectra of (A) raw Afromomum melegueta (RAM) peels and (B) quaternised Afromomum melegueta (QAM) peels

\section{Influence of $\mathrm{pH}$ on adsorption of PNP}

Batches of $0.03 \mathrm{~g}$ of the raw and quaternised adsorbents were separately weighed into screw cap bottles containing $20 \mathrm{~mL}$ of the model solution containing $30 \mathrm{mg} / \mathrm{L}$ and adjusting the $\mathrm{pH}$ of the solution to the desired values of between 3 and 9 using $0.1 \mathrm{M} \mathrm{HCl}$ or $0.1 \mathrm{M} \mathrm{NaOH}$. These mixtures were then equilibrated for 60 mins after which PNP concentration was determined using UV-Vis spectrophotometer. The results in figure 2 show the impact of $\mathrm{pH}$ on adsorption of PNP by raw and quaternised Aframomum melegueta peels (RAM and QAM). Figure 2 shows a maximum removal percentage of $88.76 \%$ and $95.32 \%$ for RAM and QAM respectively at $\mathrm{pH}$ 3. It was thus considered that $\mathrm{pH} 3$ was most favorable for the adsorption of PNP onto RAM and QAM. The reduced uptake at elevated $\mathrm{pH}$ can be attributed to rise in dissolution of PNP and the fact that the concentration of $\mathrm{OH}$ ions increases thus increasing the barrier of diffusion of the negatively charged PNP ions. The adsorption of PNP can therefore be said to be favorable at low $\mathrm{pH}$ since in its molecular form it has its $\mathrm{pH}$ being lower than $\mathrm{pKa}$ hence the increased uptake of PNP could be as a result of the bonded $-\mathrm{NO}_{2}$ which reduces the electron density in the aromatic ring since it's an electron withdrawing group. The results are coherent with those reported elsewhere (Mohamed et al., 2011; Asrar, 2013; Nurul et al., 2020) who established higher adsorption of PNP at lower $\mathrm{pH}$.

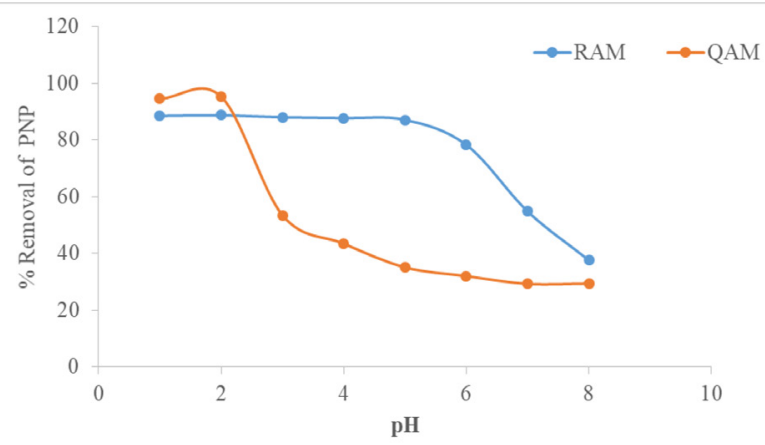

Figure 2. Impact of $\mathrm{pH}$ on the adsorption of PNP on raw and quaternised Afromomum melegueta peels (RAM \& QAM)

\section{Impact of contact time on uptake of PNP}

The influence of this parameter was investigated by having batches of $0.03 \mathrm{~g}$ of the raw and quaternised adsorbents weighed separately into screw cap bottles containing $20 \mathrm{~mL}$ of the model solution containing 30 $\mathrm{mg} / \mathrm{L}$ and adjusting the $\mathrm{pH}$ of the solution to the desired value. Contact time intervals applied were: 1, 10, 30, 50, 70, 90, 110, 130 and 150 mins. Uptake of PNP was influenced by adsorbate residence time as shown in figure 3 , the rate of uptake was rapid during first 45 minutes in the raw and quaternised Afromomum melegueta peels. However, maximum adsorption was achieved at 30 mins in RAM peels with removal percentage of $87.42 \%$ and 45 mins in QAM peels with removal percentage of 94.46 $\%$. Thereafter, the rate of PNP removal approached a steady state, indicating attainment of equilibrium. At the beginning, the accelerated adsorption rate in the first 2030 min can be attributed to physical adsorption occurring at the adsorbent surface while the decreased uptake is as 


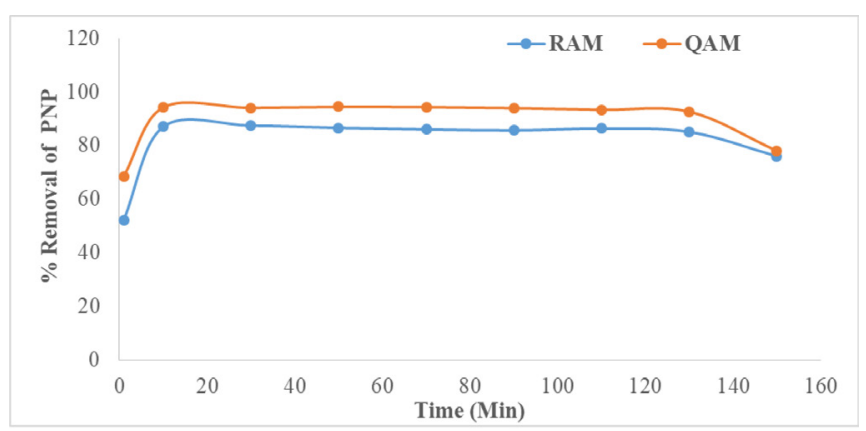

Figure 3. Impact of contact time on adsorption of PNP on raw and quaternised Afromomum melegueta peels (RAM \& QAM)

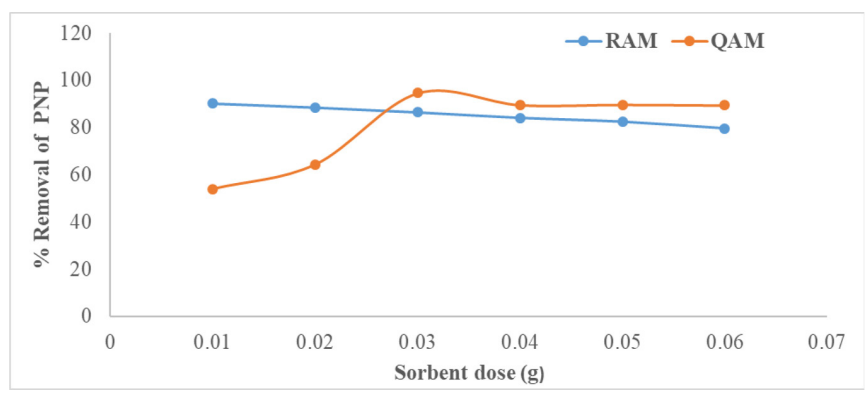

Figure 4. Effect of sorbent dose on the adsorption of PNP on raw and quaternised Afromomum melegueta peels (RAM \& QAM)

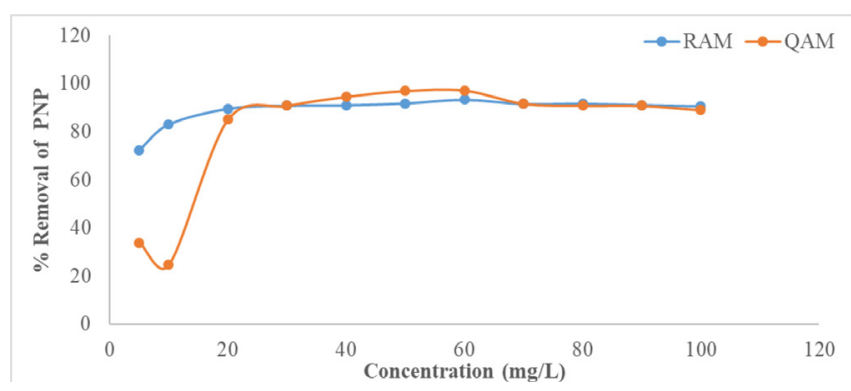

Figure 5. Influence of initial concentration on uptake of PNP by raw and quaternised Afromomum melegueta peels (RAM \& QAM)

a result of other processes such as complexation (Khani, 2006). It was established that to realize maximum uptake of PNP, contact time of 30 minutes was adequate. Increase in contact time did not show any variation in concentration. Results reported are coherent with those reported by (Mohamed et al., 2011; Mwangi et al., 2014; Prashant et al., 2016; Nurul et al., 2020).

\section{Impact of sorbent dose on uptake of p-Nitrophenol}

The influence of the amount of adsorbent on uptake of PNP was evaluated by using different sorbent dose: 0.01 ,
$0.02,0.03,0.04,0.05$ and $0.06 \mathrm{~g}$ at fixed volume of $20 \mathrm{~mL}$ containing $20 \mathrm{mg} / \mathrm{L}$ of PNP. The experiment was carried out at a contact time of $30 \mathrm{~min}$ and $45 \mathrm{~min}$ for RAM and QAM respectively and a solution $\mathrm{pH}$ of 3 . Results from figure 4 shows that uptake of PNP was influenced by adsorbent dosage. Removal percentage of PNP by RAM was highest at $0.01 \mathrm{~g}$ and further increment in weight of sorbent made the amount of PNP removed to decrease. Uptake of PNP by QAM increased rapidly from $53.91 \%$ at the dose of $0.01 \mathrm{~g}$ to $94.61 \%$ at the dose of $0.03 \mathrm{~g}$, after which it becomes almost constant. The results show that uptake of phenolate ions rises with increased sorbent doses possibly due to increase in the surface area and hence adsorption sites, this is coherent with result reported elsewhere (Asrar, 2013; Prashant et al., 2016; Nurul et al., 2020). Further increase in sorbent dose led to decreased uptake; since the sites of adsorption are laden with the sorbate besides there is solid aggregation as a result of inter particle interaction (Lataye et al., 2011). Modification improved the uptake of PNP by the adsorbent; this can be attributed to improved surface texture and micro pore structure after modification as shown in figure 5 fast-tracking the entrance of the PNP ions into sites of adsorption (Anwar et al., 2010). Since there is no increase in the adsorption beyond $0.01 \mathrm{~g}$ and $0.03 \mathrm{~g}$ for RAM and QAM, these doses were considered as the optimum adsorbent doses which were used in subsequent studies.

\section{Influence of initial concentration on adsorption}

The impact of starting concentration $\mathrm{C}_{0}(5-100 \mathrm{mg} / \mathrm{L})$ and sorbent mass of 0.01 and $0.03 \mathrm{~g}$ of RAM and QAM respectively on the removal of PNP at $\mathrm{t}=30$ minutes for RAM and $\mathrm{t}=45$ minutes for $\mathrm{QAM}$ at solution $\mathrm{pH}$ of 3 was investigated and results are shown in Figure 5. Adsorption capacity of the quaternised adsorbent was obtained by plotting the collected data as a function of PNP ion concentration adsorbed versus the initial PNP ion concentration. It was established that the amount of PNP removed rises in a linear manner and then stabilized beyond a concentration of $30 \mathrm{mg} / \mathrm{L}$ due to the fact that the fixed sorbent mass adsorbs a fixed amount of PNP at constant volume of adsorbent. The adsorbent is at this instance said to be saturated with the sorbate (Prashant et al., 2016). It was established that the uptake of PNP increases from $93.2 \%$ to $97.1 \%$ after modification. The percentage uptake of PNP using raw adsorbents was lower than that of modified adsorbents. Sorption of PNP from water is thus greatly favored by modification of the raw adsorbent since it makes the surface of the adsorbent to have a micro rough texture and porous. At low initial PNP concentration almost all the phenolate ions have been adsorbed from aqueous solution. As the initial PNP concentration is increased the efficiency of adsorption does not change due to the fact that the active 
sites available become limited (Ilhan et al., 2004; Arshad et al., 2008; Koel et al., 2012; Mwangi and Ngila, 2012; Moyo and Chikazaza, 2013). The findings compare with those reported in the study of activated carbons in removal of PNP (Mohamed et al., 2011), adsorption of phenolic compounds from water by quaternised treated maize tassels (Mwangi et al., 2014) and application of acid treated biosorbents derived from lemon, sweet yellow passion, banana, watermelon peels and avocado seeds to adsorb heavy metals (Nthiga et al., 2016).

\section{Impact of temperature on adsorption}

The uptake of PNP from solution by the raw and modified adsorbents at temperatures: $15,25,35,45,60,75,90$ is shown in Figure 6. Other experimental conditions were: solution $\mathrm{pH}$ of 3 , sorbent dosage of 0.01 and $0.03 \mathrm{~g}$ for RAM and QAM respectively, contact times of $30 \mathrm{~min}$ and 45 mins for RAM and QAM respectively and initial concentration of $30 \mathrm{mg} / \mathrm{L}$. Increase in temperature leads to decreased uptake of PNP. This could be due to the fact that increase in solution temperature leads to a rise in the solubility of PNP, hence the molecules diffusion within the adsorption sites is hindered. This is expected for physical adsorption process which in most cases is usually exothermic (Garcia et al., 2003; Li et al., 2008). It was indicated that the efficiency of adsorption was higher at $25{ }^{\circ} \mathrm{C}$, further increase in temperature lowered the amount of PNP removed Therefore adsorption isotherms were determined at $25^{\circ} \mathrm{C}$. Application of RAM and QAM peels for the uptake of PNP from water is thus applicable at ordinary room temperatures of $25{ }^{\circ} \mathrm{C}$ The findings compare with those reported in the study of removal of PNP using activated carbons derived from sewage sludge (Mohamed et al., 2011).

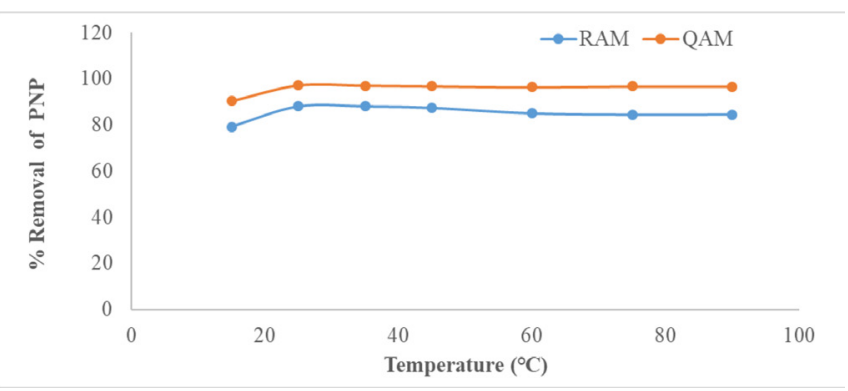

Figure 6. Influence of temperature on the adsorption of PNP on raw and quaternised Afromomum melegueta peels (RAM \& QAM)

\section{Adsorption isotherms}

The data on adsorption of PNP on RAM and QAM against initial concentration of PNP was fitted onto Langmuir and Freundlich isotherms which are presented in equations 1 and 2 respectively.

$$
\frac{C_{e}}{q_{e}}=\frac{1}{b Q_{\max }}+\frac{1}{Q_{\max }} C_{\theta}
$$

Equation 1

Where $\mathrm{C}_{e}$ and $\mathrm{q}_{e}$ are initial and equilibrium PNP concentrations, $q_{\max }$ is the adsorption capacity in $\mathrm{mg} / \mathrm{g}$ and $b$ is a Langmuir constant. The values of $q_{\max }$ and $b$ were calculated from the slope and intercept of the Langmuir isotherm equation plot of $\frac{C e}{q e}$ versus Ce which gives a straight line with $\frac{1}{q \max }$ as the intercept and $\frac{1}{b q \max }$ as the slope, from which $q_{\max }$ and $b$ can be determined.

$$
\log q_{e}=\log K_{f}+\frac{1}{n} \log C_{e}
$$

Equation 2

Where, $K_{f}$ is Freundlich sorption capacity $\frac{1}{n}$, is the adsorption intensityFor Freundlich isotherm equation, a plot of $\log _{q e}$, versus $\log _{c e}$ yields a straight line from which $K_{f}$ and $\frac{1}{n}$ can be determined from the intercept and slope respectively; $K_{f}$ and $n$ are constants representing adsorption capacity and intensity respectively.

The adsorption of PNP onto QAM gave $\mathrm{R}^{2}$ of 0.966 indicating the data fitted well in Langmuir model. The values of $b$ of 0.2081 and 0.11648 indicate favorable adsorption process for RAM and QAM, respectively. This model prescribes a single-layered adsorption and it indicates a chemisorptions process (Deng et al., 2003; Hossain et al., 2012, Mwangi and Ngila, 2012). $\mathrm{R}^{2}$ values gotten for RAM show that adsorption process fits to the Freundlich model indicating that the adsorbent has a great affinity for sorbate (Hossain et al., 2012). Adsorption capacities $\left(\mathrm{q}_{\max }\right)$ recorded by raw adsorbents were lower than those recorded by the quaternised adsorbents. This clearly shows that quaternisation improved the sorption capacities of these adsorbents. These results compare with those reported in study of quaternised maize tussles to remove chlorophenols (Mwangi et al., 2014), sewage sludge based activated carbons to remove PNP (Mohamed et al., 2011) The $\mathrm{R}^{2}$ of 0.8931 obtained in RAM indicate applicability of Freundlich model for adsorption of PNP using this adsorbent. Freundlich model prescribes a multilayer adsorption which is a descriptive of both chemisorptions and physical sorption of PNP as a result of weak Vander Waal forces (Deng et al., 2003; Hossain et al., 2012; Mwangi and Ngila, 2012). Adsorption capacity and intensity are represented by constants $K_{f}$ and $n$ 
respectively (Voudrias et al., 2002). From Table. 1 the value of $\frac{1}{n}$ observed indicates cooperative adsorption of PNP by both RAM and QAM (Dada et al., 2012). The values for $K_{f}$ for quaternised adsorbents are higher than those of the raw adsorbents as shown in table 1 , thus indicating the efficiency of the quaternisation process. This could be due to improved surface texture and micro pore structure as well as increased adsorption sites hence higher adsorption capacity for QAM than RAM. The constants for the adsorption isotherms used in this study are presented in Table 1.

Table 1. Langmuir and Freundlich constants for PNP adsorption using raw and quaternised adsorbents

\begin{tabular}{|l|l|l|l|l|l|l|l|}
\hline Ads & \multicolumn{6}{|l|}{ Langmuir isotherm } & \multicolumn{4}{l|}{ Freundlich isotherm } \\
\hline & $\begin{array}{l}\boldsymbol{q}_{\max } \\
(\mathbf{m g} / \mathbf{g})\end{array}$ & $\begin{array}{l}\boldsymbol{b}(\mathbf{L} / \\
\mathbf{m g})\end{array}$ & $\boldsymbol{R}^{2}$ & $\begin{array}{l}\boldsymbol{K}_{f} \\
(\mathbf{m g} / \mathbf{g})\end{array}$ & $\boldsymbol{n}$ & $\boldsymbol{R}^{2}$ & Best model \\
\hline RAM & 8.70 & 0.2081 & 0.6076 & 2.85 & 0.02985 & 0.8931 & Freundlich \\
\hline QAM & 106.38 & 0.11648 & 0.966 & 15.02 & 0.7170 & 0.0052 & Langmuir \\
\hline
\end{tabular}

Table 2. Adsorption capacity of different adsorbent materials for the adsorption of PNP

\begin{tabular}{|l|c|l|}
\hline Adsorbent material & $\begin{array}{l}\mathbf{q}_{\max } \\
\mathbf{( m g} / \mathbf{g})\end{array}$ & Reference \\
\hline Activated jute stick char & 39.38 & $\begin{array}{l}\text { Ahmanizzaman and } \\
\text { Gayatri (2010) }\end{array}$ \\
\hline $\begin{array}{l}\text { Salycilaldehyde modified } \\
\text { chitosan }\end{array}$ & 8.5 & $\begin{array}{l}\text { Abdel-Ghani et al. } \\
\text { (2015) }\end{array}$ \\
\hline $\begin{array}{l}\text { Olive cake based activated } \\
\text { carbon }\end{array}$ & 1.550 & $\begin{array}{l}\text { Abdel-Ghani et al. } \\
\text { (2016) }\end{array}$ \\
\hline $\begin{array}{l}\text { Activated carbon } \\
\text { impregnated with Ni }\end{array}$ & 12.48 & (Matus et al. \\
\hline $\begin{array}{l}\text { Acacia glauca } \text { activated } \\
\text { carbon }\end{array}$ & 204.79 & Prashant et al. \\
\hline $\begin{array}{l}\text { Pilli nut based activated } \\
\text { carbon }\end{array}$ & 190.39 & Nwosu et al. (2017) \\
\hline $\begin{array}{l}\text { Biochar samples } \\
\text { pyrolysed at } 300{ }^{\circ} \mathrm{C}\end{array}$ & 5.711 & Lanqi et al. (2020) \\
\hline $\begin{array}{l}\text { Biochar samples } \\
\text { pyrolysed at } 700{ }^{\circ} \mathrm{C}\end{array}$ & 117.165 & Lanqi et al. (2020) \\
\hline $\begin{array}{l}\text { Cauliflower based } \\
\text { activated carbon at } 250{ }^{\circ} \mathrm{C}\end{array}$ & 158.73 & Nurul et al. (2020) \\
\hline $\begin{array}{l}\text { Sea mango activated } \\
\text { carbon }\end{array}$ & 106.38 & Present study \\
\hline $\begin{array}{l}\text { RAM } \\
\text { QAM }\end{array}$ & & Present study \\
\hline
\end{tabular}

The adsorption capacity obtained for QAM in this study was higher than the ones obtained with activated carbon synthesized from activated jute stick char (Ahmanizzaman and Gayatri, 2010), cauliflower waste (Nidhi et al., 2020), pine saw biochar olive cake (Abdel-Ghani et al., 2016) as well as activated carbon impregnated with $\mathrm{Ni}$ (Matus et al., 2016). This could be attributed to the efficiency of the modification process that anchors a positively nitrogen atom in the cellulose structure that bonds well with the negatively charged PNP ions. However, the value obtained for QAM was lower than the one obtained with activated carbon synthesized from acacia glauca sawdust (Prashant et al., 2016), pilli nut shell (Nwosu et al., 2017), sea mango (Nurul et al., 2020), pine saw dust biochar (Lanqi et al., 2020). The comparison of adsorption capacities of RAM and QAM with previously reported adsorbent materials is presented in Table 2.

\section{CONCLUSION}

In this study, adsorption efficiency of raw and quaternised Afromomum melegueta peels towards removal of PNP from water was evaluated. Removal efficiency of PNP is high at the first 30 mins of contact and at sorbent dosage of 0.01 $\mathrm{g}$ and $0.03 \mathrm{~g}$ for RAM and QAM respectively. Quantity of PNP removed increases as the initial concentration rises however, adsorption decreases after a concentration exceeding $30 \mathrm{mg} / \mathrm{L}$. The ideal $\mathrm{pH}$ and temperature for PNP removal is at $\mathrm{pH} 3$ and $25^{\circ} \mathrm{C}$ respectively. Adsorption of PNP onto QAM and RAM follows Langmuir isotherm model and Freundlich isotherm model respectively. Raw and quaternised adsorbents showed different levels of efficiency in removing the PNP, quaternisation was shown to greatly improve the adsorption of PNP. A follow-up study is recommended on the adsorption kinetic studies as well as adsorption efficiency of the Afromomum melegueta peels for other phenolic compounds from environmental water samples.

\section{ACKNOWLEDGEMENT}

The authors are grateful to African Development Bank (AfDB) for funding the project and the assistance accorded to us by the Chemistry technicians at Kenyatta University laboratory and the support of family, friends, and colleagues.

\section{REFERENCES}

Abdel-Ghani, T., El-Chaghaby, G., \& Helal, F. (2015). Individual and competitive adsorption of phenol and nickel onto multiwalled carbon nanotubes. Journal of Advanced Research, 6, 405-415.

Abdel-Ghani, T., Rawash, A., \& El-Chaghaby, G. (2016). Equilibrium and kinetic study for the adsorption of 
p-nitrophenol from wastewater using olive cake based activated carbon. Global Journal of Environmental Science Management, 2(1), 11-18.

Agency for Toxic Substances and Disease Registry-ATSDR. (1992). Toxicological Profile for Nitrophenols (Draft) Public Health Service, U.S. Department of Health and Human Services, Atlanta, GA.

Ahmad, F., Daud, W., Ahmad, M., \& Radzi, R. (2011). Using cocoa (Theobroma cacao) shellbased activated carbon to remove 4-nitrophenol from aqueous solution: Kinetics and equilibrium studies. Chemical Engineering Journal, 178, 461-467.

Ahmad, M., Rajapaksha, A., Vithanage, M., Zhang, M., Cho, J., Lee, S., \& Ok, Y. (2013). Trichloroethylene adsorption by pine needle biochars produced at various pyrolysis temperatures. Bioresource. Technology, 143, 615-622.

Ahmaruzzaman, M., \& Gayatri, S. (2010). Batch adsorption of 4-nitrophenol by acid activated jute stick char: equilibrium, kinetics and thermodynamic studies. Chemical Engineering Journal, 158, 173-180.

Ali, I., Asim, M., \& Khan, T. (2012). Low cost adsorbents for the removal of organic pollutants from wastewater. Journal of Environmental Management, 113, 170-183.

Anwar, J., shafique, U., Washed, Z., Salman, M., \& Anwar, S. (2010). Removal of Pb (II) and Cd (II) from water by adsorption on peels of banana. Bioresource Technology, 101(6), 1752-1755.

Arshad, A., \& Najar, M. (2008). Physico-chemical adsorption treatments for minimization of heavy metal contents in water and waste waters. Journal of Science and Industrial Resources, 56, 523-539.

Asrar, A. (2013). Removal of phenol compounds from aqueous solution using coated sand filter media. Journal of Chemical and Petroleum Engineering, 14(3), 23-31.

Baccar, R., Bouzid, J., Feki, M., \& Montiel, A. (2009). Preparation of activated carbon from Tunisian olivewaste cakes and its application for adsorption of heavy metal ions. Journal of Hazardous Materials, 162, 15221529.

Bortolini, O., Conte, V., Chiappe, C., Fantin, G., Fogagnolo, M., \& Maietti, S. (2002). Epoxidation of electrophilic alkenes in ionic liquids. Green Chemistry, 4, 94-96.

Crisponi, G., Casu, M., Nurchi, M., Cesare-Marincola, F., Pivetta, T., \& Silvagni, R. (2002). Substituent effects on ionisation and ${ }^{13} \mathrm{C}$ NMR properties of some monosubstituted phenols; a potentiometric, spectrophotometric and ${ }^{13} \mathrm{C}$ NMR study. Talanta, 56, 441-449.

Dada, A., Olalekan, A., Olatunya, A., \& Dada, O. (2012). Langmuir, Freundlich, Temkin and Dubinin - Radushkevich isotherms studies of equilibrium sorption of $\mathrm{Zn}^{2+}$ unto phosphoric acid modified rice husk. Journal of Applied Chemistry, 3(1), 38-45.

Deng, S., Bai, R., \& Chen, P. (2003). Aminatedpolyacrylonitrile fibers for lead and copper removal. Langmuir, 19, 5058-5064.

Garcia, J., Beltra, F., Lvarez, P., \& Masa, F. (2003). Activated carbon adsorption of some phenolic compounds present in agroindustrial wastewater. Adsorption, 9, 107-115.

Han, R., Zhang, L., Song, C., Zhng, M., Zhu, M., \& Zhang, L. (2010). Characterization of modified wheat straw, kinetic and equilibrium study about copper ion and methylene blue adsorption in batch mode. Carbohydrate Polymers, 79, 1140-1149.

Hossain, M., Ngo, H., Guo, W., \& Nguyen, T. (2012). Biosorption of $\mathrm{Cu}$ (II) from water by banana peel based biosorbent: experiments and models of adsorption and desorption. Journal of Water Sustainability, 2, 87-104.

Ilhan, S., Nourbakhsh, M., Kilicarslan, S., \& Ozdag, H. (2004). Removal of chromium, lead and copper from industrial waste by Staphylococcus saprophyticus. Turkish Electronic Journal of Biotechnology, 2, 50-57.

Ilic, N., Rosco, E., \& Schum, K. (2010). Toxicological evaluation of grains of paradise (Aframomum melegueta). Journal of Ethnopharmacol, 32, 49-59.

Isoda, N., Rodrigues, R., Silva, A., Gonçalves, M., Mandelli, D., Figueiredo, F., \& Carvalho, W. (2014). Optimization of preparation conditions of activated carbon from agriculture waste utilizing factorial design. Powder Technology, 256, 175-181.

Khani, M. (2006. Biosorption of uranium from aqueous solutions by nonliving biomass of marine algae, Cystoseira indica. Journal of Biotechnology, 9(2), 101108.

Koel, B., Ramesh, S., Gandhimathi, P., \& Bharathi, K. (2012). A novel agricultural waste adsorbent, watermelon shell for the removal of copper from aqueous solution. Journal of Iranica Energy and Environments, 3(2), 143-156.

Lanqi, L., Guozhi, D., \& Xianyang, S. (2020). Adsorption characteristics and mechanism of $p$-nitrophenol by pine sawdust biochar samples produced at different pyrolysis temperatures. Scientific Reports, 10, 1-11.

Lataye, H., Mishra, M., \& Mall, D. (2011). Removal of 4-picoline from aqueous solution by adsorption onto bagasse fly ash and rice husk ash: equilibrium, thermodynamic, and desorption study. Journal of Environmental Engineering, 137(11), 1048-1057.

Li, Y., Sun, S., Ma, M., Ouyang, Y., \& Yan, W. (2008). Kinetic study and model of the photocatalytic degradation of rhodamine $\mathrm{B}(\mathrm{RhB})$ by a $\mathrm{TiO}_{2}$-coated activated carbon catalyst: effects of initial $\mathrm{RhB}$ content, light intensity and $\mathrm{TiO}_{2}$ content in the catalyst. 
Chemical Engineering Journal, 142, 147-155.

Matus, C., Camú, E., Villarroel, M., Ojeda, J., \& Baeza, P. (2016). Study of the removal of 4-nitrophenol from aqueous media by adsorption on different materials. Journal of the Chilean Chemical Society, 61(2), 28982902.

Merkel, K., Rydarowski, H., Kazimierczak, J., \& B1oda, A. (2014). Processing and characterization of reinforced polyethylene composites made with lignocellulosic fibres isolated from waste plant biomass such as hemp composition. Part B. Journal of Engineering, 67, 138144.

Mittal, A., Mittal, J., Malviya, A., \& Gupta, V. (2010). Removal and recovery of chrysoidine $\mathrm{Y}$ from aqueous solutions by waste materials. Journal of Colloidal Interface Science, 344, 497-507.

Mohamed, E., Andriantsiferana, C., Wilhelm, A., \& Delmas, H. (2011). Competitive adsorption of phenolic compounds from aqueous solution using sludge based activated carbon. Environmental Technology, 1, 1-12.

Moyo, M., \& Chikazaza, L. (2013). Bioremediation of Lead (II) from polluted wastewaters employing sulphuric acid treated maize tassel biomass. Journal of Chemistry and Ecology, 5, 689-695.

Mwangi, I., \& Ngila, C. (2012). Removal of heavy metals from contaminated water using ethylenediaminemodified green seaweed (Caulerpa serrulata). Physics and Chemistry of the Earth, 50(52), 111-120.

Mwangi, I., Ngila, C., Ndung'u, P., \& Msagati, T. (2014). Removal of phenolics from aqueous media using quaternised maize tassels. Journal of Environmental Management, 134, 70-79.

Nidhi, Y., Dhruv, N., Shalu, R., \& Jiwan, S. (2020). Adsorption and equilibrium studies of phenol and paranitrophenol by magnetic activated carbon synthesized from cauliflower waste. Environmental Engineering Research, 25(5), 742-752.

Nthiga, E., Murungi, J., Wanjau, R., \& Hassanali, A. (2016) Application of chemically modified avocado seed for removal of Copper (II), Lead (II), and Cadmium (II) ions from aqueous solutions. International Journal of Research in Engineering and Applied Sciences, 6(8), $1-15$.

Nurul, Z., Nor, W., Umi, F., \& Tan, R. (2020). Adsorption of 4-Nitrophenol from wastewater using sea mango (Cerbera odollam) based activated carbon. Materials Science and Engineering, 778, 1-10.

Nwosu, F., Adekola, F., \& Salami, A. (2017). Adsorption of 4-Nitrophenol using pilli nut shell active carbon. Pakistan Journal of Analytical and Environmental Chemistry, 18(1), 69-83.

Parida, K., \& Prakasini, D. (2004). Photo-oxidation of 4-nitrophenol in aqueous suspensions, catalysed by titania intercalated zirconium phosphate $(\mathrm{ZrP})$ and titanium phosphate (TiP). Journal of Photochemistry and Photobiology, A: Chemistry, 163(3), 561-567.

Pavia, D., Basser, M., \& Morrill, T. (1996). Introduction to spectroscopy. Second ed. Saunders College Publishers, New York.

Pourkhanali, K. (2018). Performance evaluation of bulk liquid membrane technique on p-Nitrophenol removal from aqueous solution. Chemical and Biochemical Engineering Quarterly, 32, 83-90.

Prashant, T., Dilip, H., \& Ramakant, S. (2016). Removal of 4-nitrophenol from aqueous solution by adsorption onto activated carbon prepared from Acacia glauca sawdust. Water science and technology, 73(4), 955-966.

Stuart, B. (1996). Modern infrared spectroscopy. John Wiley \& Sons. Inc., New York.

Suja, E., Nancharaiah, Y., \& Venugopalan, V. (2012). $p$-Nitrophenol biodegradation by aerobic microbial granules. Applied Biochemistry and Biotechnology, 167, 1569-1577.

Víctor, M., Ochando-Pulido J., \& Martínez-Férez, A. (2016). Phenols removal from industrial effluents through novel polymeric resins: kinetics and equilibrium studies. Separation and Purification Technology, 160, 136-144.

Villegas L., Mashhadi, N., Chen, M., Mukherjee, D., Taylor, K., \& Biswas, N. (2016). A short review of techniques for phenol removal from wastewater. Current Pollution Reports, 2, 157-167.

Voudrias, E., Fytianos, F., \& Bozani, E. (2002). Sorption description isotherms of dyes from aqueous solutions and waste waters with different sorbent materials, Global Nest International Journal, 4(1), 75-83.

Zhao, P., Feng, X., Huang, D., Yang, G., \& Astruc, D. (2015). Basic concepts and recent advances in nitrophenol reduction by gold- and other transition metal nanoparticles. Coordination Chemistry Reviews, 287, 114-136.

Zheng, H., Guo, W., Li, S., Chen, Y., Wu, Q., Feng, X., Yin, R., Ho, S., Ren, N., \& Chang, J. (2017). Adsorption of p-nitrophenols (PNP) on microalgal biochar: analysis of high adsorption capacity and mechanism. Bioresource Technology, 244, 1456-1464.

Xia, L., Engel, K., Zhou, M., \& Wang, J. (2007). Membrane localization and $\mathrm{pH}$ dependent transport of a newly cloned organic cation transporter (PMAT) in kidney cells. American Journal of Physiology-Renal Physiology, 292, 682-690. 